\title{
Spatial dependence of calanoid copepod diversity in the North Atlantic Ocean
}

\author{
Grégory Beaugrand $^{1, *}$, Frédéric Ibañez ${ }^{2}$ \\ ${ }^{1}$ Sir Alister Hardy Foundation for Ocean Science, The Laboratory, Citadel Hill, Plymouth PL1 2PB, United Kingdom \\ ${ }^{2}$ Observatoire Océanologique, Laboratoire d'Océanologie Biologique et Écologie du Plancton Marin, \\ ESA 7076, BP 28, 06230, Villefranche sur mer, France
}

\begin{abstract}
Ecosystems are fundamentally structured in space and time. The identification and quantification of scales of variability has occupied a central place in ecology for several decades. This paper examines spatial changes in the diversity of calanoid copepods and its regional dependence in the North Atlantic Ocean at diel, seasonal and interannual scales. Point cumulative semi-variograms, initially proposed for geological purposes, are described and intensively used to understand the relationships between diversity and its spatial scales of variability. A map of the mean spatial dependence in calanoid diversity is then proposed and diel and seasonal changes examined. This shows that diversity changes at small spatial scales over the European shelf seas. In oceanic areas, diversity changes at large spatial scales in both the subarctic and the northern boundary of the subtropical gyres. Low spatial scales of variability are detected in the Gulf Stream extension, in the path of the North Atlantic Current and west of Europe. A negative relationship between diversity and its spatial dependence is found in almost all the oceanic regions. This relationship is constant at all temporal scales. At an annual scale, relationships between diversity, spatial dependence and climatic indices have been investigated. Some links have been detected but both the intensity and the sign of these relationships vary greatly in space. The regime shift that took place in the North Sea after 1988 involved a sharp change in the diversity of calanoid copepods and a significant strengthening in the contrast between the neritic and oceanic spatial dependence.
\end{abstract}

KEY WORDS: Spatial scale of variability · Point cumulative semi-variograms · Calanoid copepods · Pelagic diversity · Continuous Plankton Recorder (CPR) survey

\section{INTRODUCTION}

Ecosystems are fundamentally structured in space and time (Margalef 1979, Frontier \& Pichot-Viale 1993, Lundberg et al. 2000), and the identification and the quantification of scales of variability has been a topic of great importance in ecology for several decades (e.g. Levin 1992, Mann \& Lazier 1996, Haury \& McGowan 1998, Beaugrand et al. 2001). Haury et al. (1978), by the use of a 3-dimensional time-space plot (Stommel 1963), estimated the spatial and temporal structure of zooplankton biomass variability. At all spatial scales, physical features often represented important factors

*E-mail: gbea@mail.pml.ac.uk involved in the control of spatial and temporal patterns of biomass variability. Similar conclusions have been subsequently found (e.g. Platt \& Sathyendranath 1994, Mann \& Lazier 1996, Haury \& McGowan 1998, Beaugrand et al. 2002, this issue).

Many techniques are available to quantify and analyse the temporal variability of biological variables (e.g. Diggle 1990, Ibañez \& Etienne 1991, Legendre \& Legendre 1998). For example, Colebrook (1981, 1982, 1985, 1991) and Colebrook \& Taylor (1984) applied maximum entropy spectral analysis to determine the characteristic frequency of the long-term change in the abundance of plankton around the United Kingdom. One-dimensional spectral analysis has also been applied to examine spatial scales of variability of 
biological variables such as chlorophyll fluorescence and copepod abundance (Tsuda et al. 1993) or physical variables (Yoder et al. 1993). Moran's (1950) or Geary's (1954) spatial autocorrelation coefficients can also be used to assess the scales of variability involved in the changes of organism abundance. Semi-variograms, proposed for the first time by Matheron (1962), are also often applied to identify spatial behaviour of a biological variable at different spatial scales (e.g. Planque 1996, Grioche et al. 1997). For example, Planque (1996) used experimental semi-variograms to examine the spatial scale of variability of Calanus finmarchicus and C. helgolandicus for different months across the North Atlantic Ocean.

However, the application of these techniques to assess the spatial variability of a variable is limited. For example, classical experimental semi-variograms are highly sensitive to the non-regularity of the distribution of observations inside a given spatial domain (Sen 1989, Wackernagel 1995). Sampling by many monitoring programmes such as the Continuous Plankton Recorder (CPR) survey is irregular in space, and thus an unbiased estimation of experimental semi-variogram is not possible. Moreover, the choice of distance classes in the building of the experimental semi-variogram is quite arbitrary and may highly influence the shape of the curve (Sen 1989). These drawbacks led Sen (1989) to propose a new way to evaluate the spatial dependence of observations for geological purposes.

This method, known as the point cumulative semivariogram, has been applied in this paper to evaluate the spatial dependence of the diversity of calanoid copepods in the North Atlantic Ocean at 3 temporal scales of variability: diel, seasonal and annual scales. Firstly, as this technique has never been used in oceanography, a full description of its potentialities is given. Secondly, this method is used to characterise the mean spatial variability of the diversity of calanoid copepods at diel, seasonal and annual scale over the North Atlantic Ocean. Thirdly, the mean spatial relationships between the diversity and its spatial dependence are investigated. Finally, Sen's point cumulative semi-variogram is applied to study annual and longterm changes in the diversity and its spatial dependence in relation to climatic indices such as the North Atlantic Oscillation (NAO), the northern hemisphere temperatures and the regime shift in the North Sea marine ecosystems (Reid et al. 2001a).

\section{MATERIALS AND METHODS}

Biological data. Biological data used in this study were collected from the CPR survey. This biological monitoring programme has sampled plankton on a monthly basis over the North Atlantic and adjacent seas since 1946 (Warner \& Hays 1994). Samples are collected by a high-speed plankton recorder towed behind voluntary merchant ships at a standard depth of about $6.5 \mathrm{~m}$ (Hays 1994). Plankton is retained by a continuously moving band of silk, which has an average mesh size of $270 \mu \mathrm{m}$, corresponding to approximately $3 \mathrm{~m}^{3}$ of filtered seawater (Hays 1994). One CPR sample represents $10 \mathrm{n}$ miles of tow. A complete description of this programme is given by Colebrook $(1960,1975)$ and Warner \& Hays (1994). In the present study, data of 108 copepod taxa, corresponding to the sampling period 1958 to 1999, were extracted from the CPR database.

Climatic data. Two climatic indices were used to assess the relationships between diversity, its spatial dependence and climatic factors. Temperature anomalies for the northern hemisphere from 1958 to 1998 were provided by the Hadley Centre for Climate Prediction and Research, Meteorological Office, London. The winter NAO index (Hurrell 1995) for the period 1958 to 1999 was obtained from the Internet site: www.met.rdg.ac.uk/cag/NAO/index.html. The NAO is a basin scale alternation of atmospheric mass over the North Atlantic between the high pressures centred on the Azores and low pressures around Iceland (Dickson \& Turrell 2000). The index used here is based on the differences in normalized sea level pressure between Lisbon, Portugal and Stykkisholmur/Reykjavik, Iceland since 1864 (Hurrell 1995).

Geostatistical analyses. All analyses presented in this study have been performed on the total number of calanoid copepod species or taxa per CPR sample (Beaugrand et al. 2000, 2001). This index represents a reliable indicator of the diversity for the CPR data (Beaugrand \& Edwards 2001). This will be referred to as calanoid diversity thereafter. Experimental semivariograms and point cumulative semi-variograms were then calculated at diel, seasonal and annual scales.

Calculation of geographical distances: The locations of all CPR samples are recorded as latitudinal and longitudinal points. Before the calculation of semivariograms and point cumulative semi-variograms, longitude and latitude of each sampling site were converted into geographical distances (Step 1 in Fig. 1) using:

$$
\begin{gathered}
h_{i, j}=\arccos \left(\sin \varphi_{i} \sin \varphi_{j}+\cos \varphi_{i} \cos \varphi_{j} \cos g\right) \\
d(i, j)=6377.221 \times h_{i, j}
\end{gathered}
$$

$d(i, j)$ is the distance (in $\mathrm{km}$ ) between $i$ and $j . \varphi_{i}$ is the latitude (in radians) at point $i$ and $\varphi_{j}$ the latitude at point $j_{i}$ and $g$ is the difference in longitude between $i$ and $j$. The constant in Eq. (2) is the Earth radius in $\mathrm{km}$.

The experimental semi-variogram: The experimental semi-variogram (Matheron 1962), $\gamma_{d}$, is based on the 


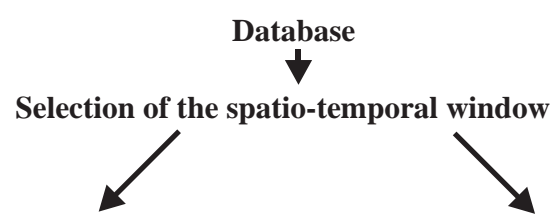

Step 1. For each site, calculation of geographical distances between the concerned site and the others (Eqs. $1 \& 2$ )
Step 2. For each site, calculation of the half-squared differences between the data value at the concerned site and data values at the other ones (Eq. 4)

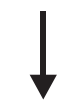

Step 3. For each site, sort distances by increasing order and rearrange the corresponding PCSV values

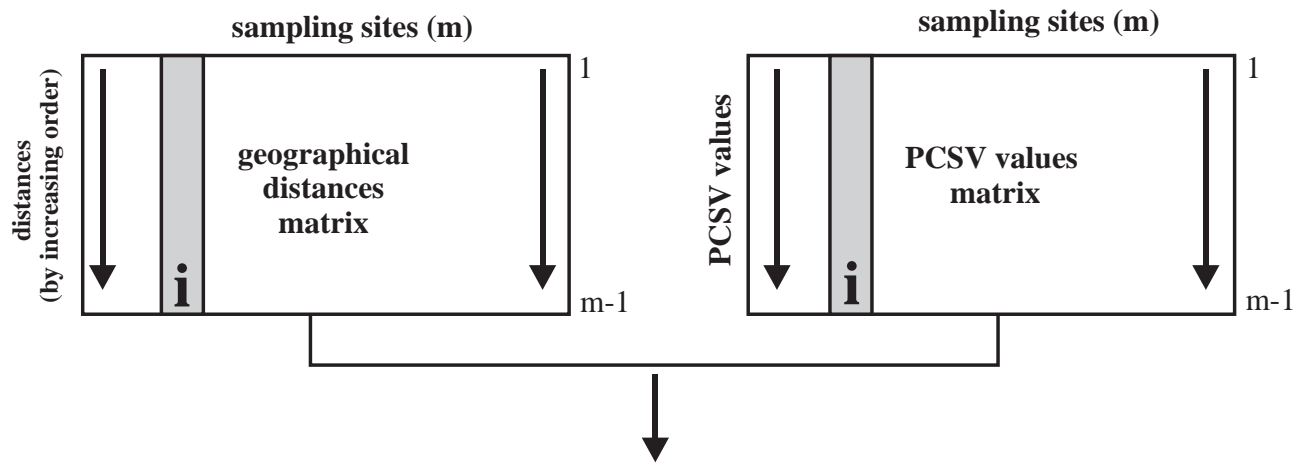

Step 4. Examination of shape of individual point semi-cumulative variograms

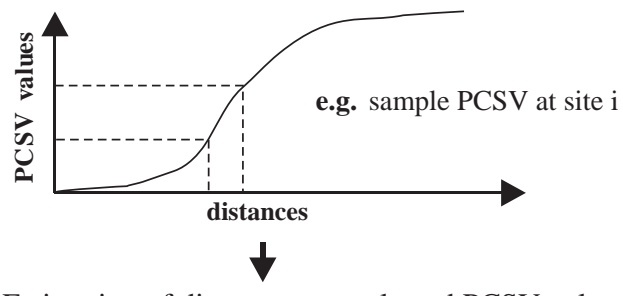

Step 5. Estimation of distances at a selected PCSV value

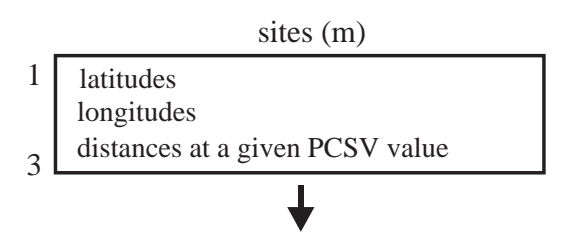

Step 6. Spatial interpolation of distances at a given PCSV value

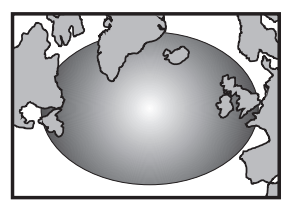

Fig. 1. Summary of the procedure used to calculate the Sen's Point Cumulative SemiVariogram and to produce maps of regional dependence of calanoid diversity

calculation of half-squared differences of all pairs of values of a measured variable (Wackernagel 1995). The plot of dissimilarities $\gamma_{\mathrm{d}}$ against the spatial separation of sample pairs defined a variogram cloud. As cloud variograms are often highly variable at short distances, the variogram has been calculated by averaging values of all half-squared differences inside predefined distance classes (Journel \& Huijbregts 1978). This leads to the following formula:

$$
\gamma_{\mathrm{d}}=\frac{1}{2 n_{\mathrm{d}}} \sum_{i=1}^{n_{\mathrm{d}}}\left(Z_{i}-Z_{i+h}\right)^{2}
$$

where $\gamma_{d}$ is value of the semi-variogram for each distance class defined by vector d. $n_{\mathrm{d}}$ is the number of 
possible dissimilarities inside the distance class d. $z_{i}$ and $z_{i+h}$ are the 2 measured variables separated by a distance $h$, with $h \in$ distance class $\mathbf{d}$.

Sen's point cumulative semi-variogram (PCSV): The general procedure used to calculate this function and to exploit potentialities of the model in this study is summarised by Fig. 1. In contrast to the experimental semi-variogram, a point cumulative semi-variogram (PCSV) (Sen 1989, 1998) is performed for each sampling site inside a spatial domain. This model is based on the same dissimilarity measure involved in the calculation of the experimental semi-variogram (Step 2 in Fig. 1). However, for each site, distances calculated between the concerned site and the other ones are sorted in an ascending order and the corresponding dissimilarities are progressively pooled (Step 3 in Fig. 1). This can be formulated as follows:

$$
\gamma_{\left(\mathrm{d}_{i}\right)}^{*}=\frac{1}{2} \sum_{j=1}^{m-1}\left(Z_{C}-Z_{j}\right)^{2}
$$

where $\mathrm{d}_{i}$ is the $i$ th site at which the PCSV is calculated between the measured variable $Z_{C}$ at the concerned site and variables $Z_{j}$ of site $j_{i} m$ is the total number of sites (or sampling points). There are, therefore, as many cumulative semi-variograms as samples. This allows the spatial dependence of the regional variable to be locally examined (Sen 1989, 1998). Here, spatial dependence is defined as the distance (in $\mathrm{km}$ ) for a given PCSV value. If this distance is relatively small, the dependence between observations is more local, which means that the regional variable varies at a low spatial scale. If the distance is higher for the same PCSV value, the spatial dependence between observations is more regional, which means that the regional variable changes at a larger spatial scale.

General procedure used to map the spatial dependence of calanoid diversity: The heterogeneity of the regional variable can be evaluated by plotting PCSV values against geographical distances (or other type of distances) for each site (Step 4 in Fig. 1). However as there are as many experimental PCSVs as points, the spatial heterogeneity of the regional variable can also be assessed numerically by determining the distance at a fixed PCSV value for each site (Step 5 in Fig. 1) and then interpolating and representing these distances on a map (Step 6 in Fig. 1). This gives an indication of the local behaviour of the variability of the regional variable. For example, anisotropic behaviour can be easily detected by simple examination of the map. The PCSV is selected by trial and error. Elevated PCSV values may be less reliable as the number of samples decreases with the distance from which the experimental cumulated semi-variogram is calculated. On the other hand, the selection of too small a PCSV value may just reflect a noisy signal or a variability related to the sampling instrument.

To determine the distance at a fixed PCSV level, a weighted mean of the superior and inferior distances was calculated. These distances were then mapped using the inverse squared distance method (Lam 1983) on latitudes and longitudes converted in Lambert coordinates to avoid a strong alteration of distances on the map (Planque et al. 1997, Beaugrand et al. 2000, Beaugrand et al. 2001). These analyses were programmed in MATLAB.

Mapping of the mean spatial dependence of calanoid diversity. To produce a map representing the average spatial dependence of calanoid diversity, the same procedure used by Beaugrand et al. (2000) to map the diversity (1958 to 1997) of this same taxonomic group was applied. Maps of diversity and spatial dependence (see Fig. 1) were produced for each year and each season (December to February, March to May, June to August, September to November) for daylight and dark periods from 1958 to 1999. A PCSV value of 100 was fixed by trial and error. The inverse squared distance method was used to interpolate spatially the distances. Search radius was fixed to $250 \mathrm{nmile}$ and the number of neighbours was constant and equal to 10. The size of the pixels was equal to $50 \mathrm{nmile} \mathrm{e}^{2}$. The size of the pixel was selected by trial and error but also corresponds with the size used by Planque \& Fromentin (1996) for the same kind of dataset. This represents a good compromise between the spatial size of a CPR sample (10 n mile) and the spatial density of the CPR sampling. Then, values of each pixel for different periods were averaged to produce a map for each season for daylight and dark periods. The function described by Beaugrand et al. (2001, their Fig. 1) was used to produce maps of spatial dependence for daylight and dark periods.

To examine the relationships between diversity and spatial dependence, a method based on the Merriam \& Sondergard (1988) Reliability Index procedure was used. This method consists of calculating correlation in a moving window centred on each possible pixel for 2 maps of identical dimensions. This procedure allows regional relationships between 2 maps to be visualised. Selected by trial and error, a window of 11 pixels (along longitudes) $\times 11$ pixels (along latitudes) was used. The Pearson correlation coefficient was then calculated between all possible pairs of values $\left(11^{2}=121\right)$ if the number of non-missing data was superior or equal to 70. Probability maps of the values of the correlation coefficient will not be displayed as with the spatial interpolation procedure, data are not spatially independent. 
Annual maps of diversity and spatial dependence. From 1958 to 1999, annual maps of diversity and spatial dependence were built by averaging 8 base maps produced for each year (4 seasons for daylight and dark periods). Correlation analyses (Pearson linear correlation coefficient) were performed for each pixel to try to establish if there were any relationships between diversity, spatial dependence and climatic indices. Probabilities were calculated with and without the consideration of autocorrelation. Box-Jenkins (1976) autocorrelation function modified by Chatfield (1989) was used in each pixel. Then, the correction using the Chelton's (1984) formula was applied as Pyper \& Peterman (1998) showed that this type of correction gave better results than the Garret-Petrie (1981) method and more stable results than the Kope \& Botsford (1990) method.

Differences in the diversity of calanoids and its spatial dependence between the period 1958-1987 and 1988-1999. Reid et al. (2001a,b) have recently suggested that a regime shift in the North Sea ecosystems took place circa 1988. To test this hypothesis and to examine its geographical extent, the annual diversity and its spatial dependence was grouped into 2 periods: 1958 to 1987 and 1988 to 1999. The mean diversity and spatial dependence values were then calculated and a Kruskal-Wallis test was performed between years of the 2 different periods for each pixel to assess the probability of observed changes.

\section{RESULTS}

\section{Sample point cumulative semi-variograms}

In order to illustrate Sen's PCSV model, data were firstly selected in the North Atlantic Ocean from 1960 to 1980 for August, using only night data (Fig. 2a). The regional experimental semi-variogram (Fig. 2b) calculated from these data shows that the diversity of calanoid copepods is spatially dependent up until about $1200 \mathrm{~km}$ where the semi-variogram levelled off. A sill (the value of the variogram at the distance from which the variance ceases to increase) of approximately 8 was identified corresponding to the range of $1200 \mathrm{~km}$. A nugget effect (the value of the variogram for distance 0) of about 2.25 was detected, which indicates sampling-related variance or variability at a small spatial scale.

Fig. 2c-f displays the experimental PCSVs for 4 selected samples in the North Atlantic Ocean. The shapes of the 4 PCSVs are different, which reflects the presence of at least 4 regions of distinct pattern of spatial variability in the diversity of calanoids and indi- cates that the selected region is spatially heterogeneous (Sen 1989, 1998). All experimental PCSVs have a small portion where the PCSV values are weak or equal to 0 for a distance ranging between 0 and 100 to $250 \mathrm{~km}$. This means that a small (or no) change in the diversity of calanoid copepods occurs around this range and thus that a physical process may be responsible for homogenisation of the diversity in these areas. Curvature portions present in all sample PCSVs indicate a spatial dependence of value of diversity for calanoid copepods while the straight lines following these portions indicate that calanoid diversity becomes spatially independent. Flattened portions at large distances (Fig. 2c) may sometimes occur because of a scale effect on the curve. It should also be noted that the last portion of PCSVs only contains a few points indicating that caution should be taken with the interpretation.

While it is difficult to interpret the experimental semi-variogram in Fig. 2c, the sample PCSV clearly shows a strong spatial dependence around the station concerned until at least $1200 \mathrm{~km}$ in the Atlantic Arctic Province (Longhurst 1998). The sample PCSVs (Fig. 2d) at a site located in the northern part of the North Atlantic Drift Province (Longhurst 1998) has a similar shape to the former PCSV. However, the spatial dependence around the site is $50 \%$ weaker at the PCSV cut-off of 1000 . Using the local semi-variograms performed for each site, this difference, easy to identify by the examination of sample PCSVs, is difficult to detect by looking at the corresponding experimental semi-variograms.

The sample PCSV in the northern part of the subtropical gyre (Fig. 2e) exhibits successive curvature portions which means that the spatial variability in the diversity of calanoids is controlled by different physical processes which act at different spatial scales. Off Newfoundland (Fig. 2f), the PCSV is similar to the former with a $50 \%$ decrease of the spatial dependence at a PSCV value of 1000. Here also, this difference would have been difficult to detect by examination of the sample semi-variograms at the 2 sites.

\section{Mapping of the spatial dependence}

In practice, as there are as many PCSVs as sites, it is not possible to examine all graphics. However, the spatial dependence can be assessed by fixing a PCSV value and numerically determining the corresponding distances for all plots. Interpolation methods can be then used to map the spatial dependence of the regional variable. At a given site for a fixed PCSV value, the smaller the distances are, the more 
a. geographical distribution of samples (1678)
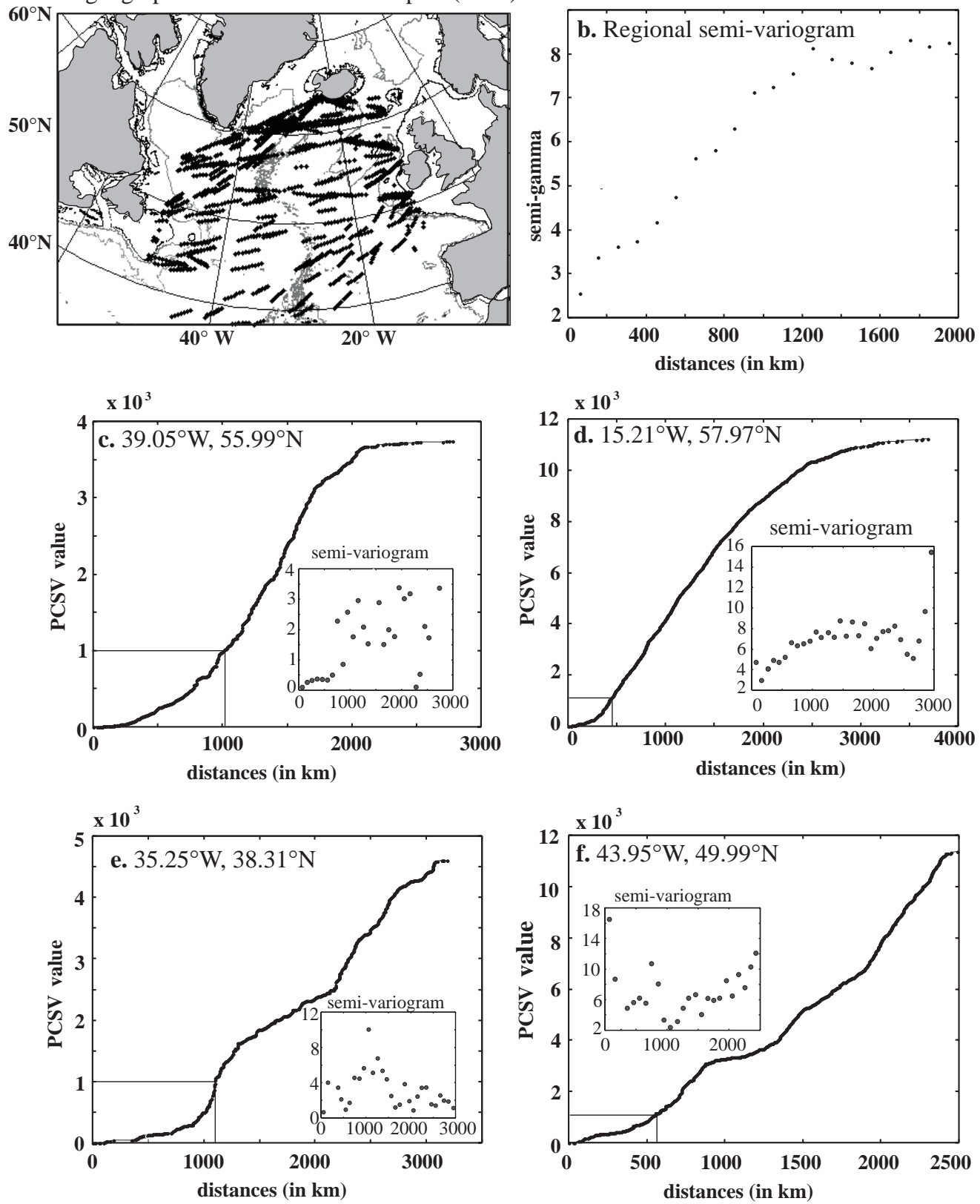

Fig. 2. Experimental semi-variograms and PCSVs calculated in the northern North Atlantic Ocean in August for the period 1960 to 1980 (1678 samples collected during dark periods). (a) Geographical distribution of samples. (b) Regional experimental semivariogram of the diversity of calanoid copepods. (c to f) Experimental PCSVs and local semi-variograms of the calanoid diversity at some sites. Dark periods were selected using the function presented in Beaugrand et al. (2001, their Fig. 1)

local the variability, and the more regional the spatial dependence between observations (large-scale variability).

Fig. 3 shows the results of this procedure for 3 PCSV values (200, 500 and 1000). Results in the 3 maps are similar. The spatial dependence is high in the subarctic and subtropical gyres. At the PCSV threshold of 200, calanoid diversity (as the mean number of taxa per
CPR sample) varies at about 500 and $600 \mathrm{~km}$ on average in both gyres. Between these gyres, an area of lower-scale spatial variability is detected, which highly corresponds with the path of the North Atlantic Current west of the mid-Atlantic ridge (Beaugrand et al. 2001). Another area of lower-scale spatial variability is found in the northern part of the North Atlantic Drift Province (Longhurst 1998). 
Mean spatial dependence of the diversity of calanoids in the North Atlantic Ocean

Using all CPR samples from the period 1958 to 1999 in the North Atlantic and adjacent seas, the same procedure described above to assess the spatial dependence was applied for each season for daylight and dark periods. Diversity of calanoids was also calculated for the same periods. Fig. 4a shows the calanoid diversity in subsurface waters for dark periods. This map is very similar to that produced by Beaugrand et al. (2000) for the period 1958 to 1997 and there is no need to comment on it here. Fig. 4b displays the mean spatial dependence of calanoid diversity for dark periods. In oceanic regions, both subtropical (northern part) and subarctic gyres have the strongest spatial dependence. A more local variability is detected between the 2 gyres and west of Europe. A gradient between oceanic and neritic regions is quite visible on both sides of the North Atlantic Ocean.

In general, the correlation between each pixel of both the diversity and spatial dependence maps is negative $(r=-0.61$, $\mathrm{df}=1169$ ). The probability is highly significant $(p<0.0001)$. However as the use of spatial interpolation involves a high spatial autocorrelation, the probability should be considered with caution. Calculation of the local correlation coefficient (using a spatial window of 11 pixels $\times 11$ pixels) indicates that the relationships between diversity and its spatial dependence are negative throughout nearly all the regions (Fig. 4c). This means that the smaller the scale at which the spatial variability changes, the higher the diversity is. This relationship is weaker over the European shelf edge and in the Bay of Biscay. A positive relationship is detected over the Grand Banks, south of Greenland and in the North Sea.

\section{Spatial dependence at diel and seasonal scales}

Maps of the spatial dependence of diversity of calanoids for daylight and dark periods (not shown) show similar spatial patterns but diversity spatially changes at a. PCSV cutoff $=200$

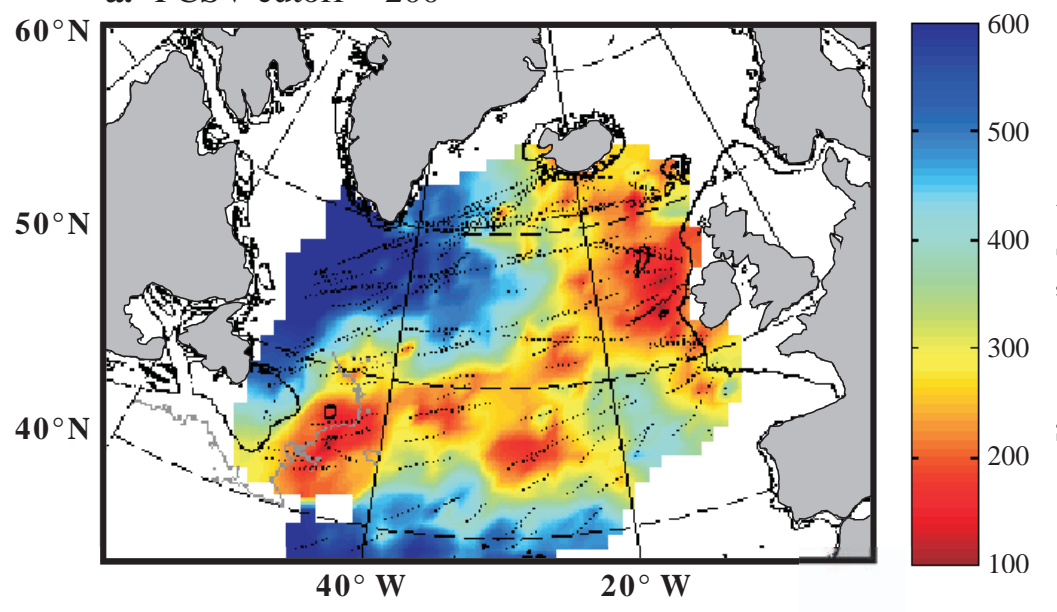

国

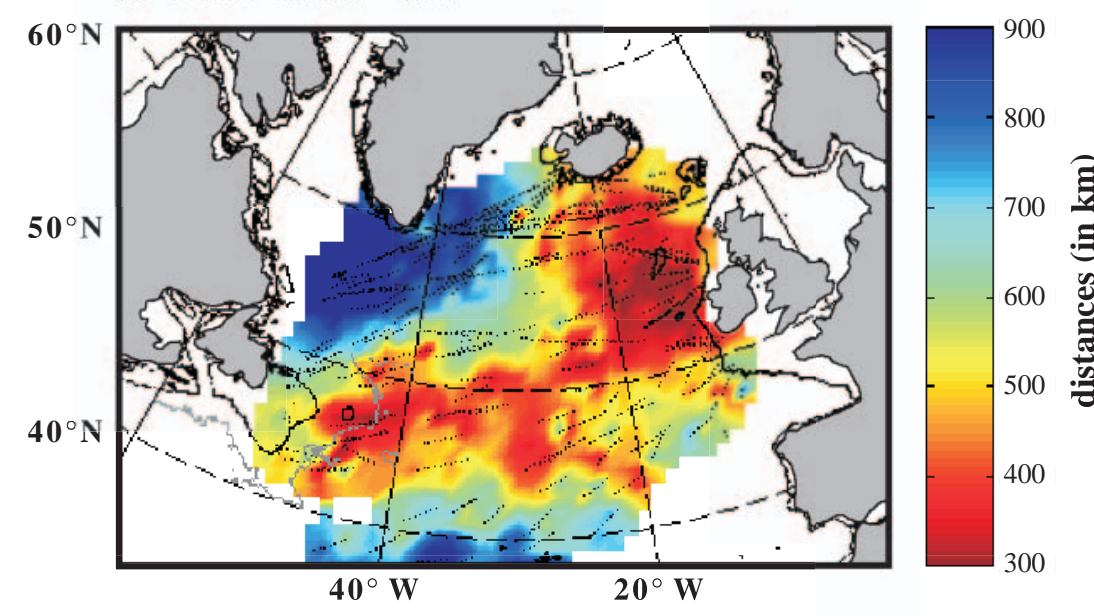

\section{c. PCSV cutoff $=1000$}

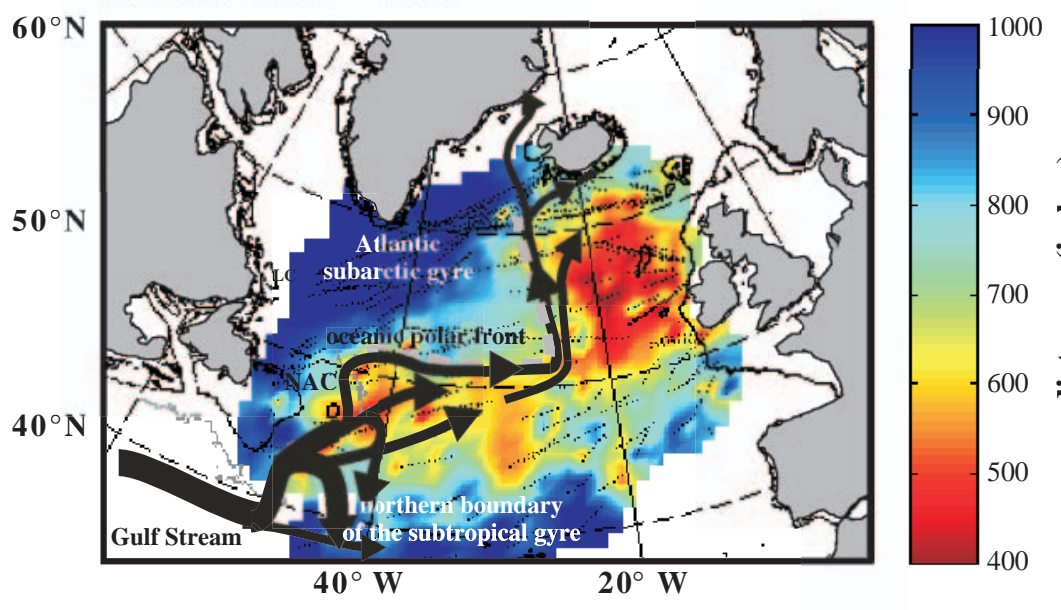

Fig. 3. Maps of the mean regional dependence of the calanoid copepod diversity in the North Atlantic Ocean in August (dark data) for the period 1960 to 1980. (a) PCSV level of 200. (b) PCSV level of 500. (c) PCSV level of 1000. The path of the North Atlantic Current is superimposed (Beaugrand et al. 2001) 
a smaller scale at night. At a seasonal scale (Fig. 5), patterns of spatial scale of change in the diversity between different seasons are stable overall. Spatial variability in calanoid diversity occurs at a higher scale in winter. From spring, spatial variability is lower and reaches a minimum in autumn. A stronger seasonal change is detected in the north-eastern part of the North Atlantic province (Longhurst 1998).

\section{Diversity, spatial dependence and climatic indices}

Annual maps of calanoid diversity and its regional variability were produced. Fig. $6 a, b$ shows the correlations between annual changes in calanoid diversity and the winter NAO index, and between calanoid diversity and northern hemisphere temperatures. Significant negative correlations are detected in the oceanic areas while positive relationships are found in the north-eastern part of the North Sea. Positive correlations between diversity and northern hemisphere temperatures seem to occur in the north-eastern part of the North Sea. However, probabilities become insignificant when the temporal autocorrelation is corrected.

Fig. 6c,d displays the correlation maps between spatial dependence and winter NAO index, and between regional dependence and northern hemisphere temperatures. A significant positive link is detected between regional dependence in the diversity of calanoids and the $\mathrm{NAO}$ in oceanic areas west of the British Isles. In other areas, the correlations are more negative. The same pattern is seen when the correlations between spatial dependence and northern hemisphere temperatures are examined. However, the contrast between both regions is emphasised. Again, when the autocorrelation is considered, this pattern becomes insignificant.

\section{Influence of the regime shift of the North Sea on the calanoid diversity and its spatial dependence}

Annual maps of calanoid diversity and spatial dependence have been grouped into 2 periods: 1958 to 1987 and 1988 to 1999. A clear shift in the spatial distribution of diversity occurred after 1987 (Fig. 7a). Diversity decreased considerably in the west European basin and west of the British Isles after 1987. A clear increase

\section{a. Mean diversity}
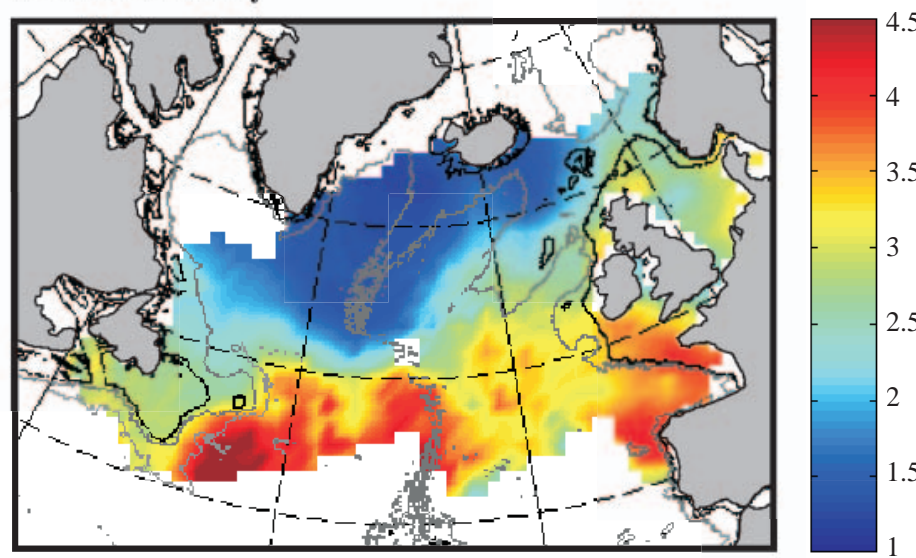

4.5

b. Mean regional dependence
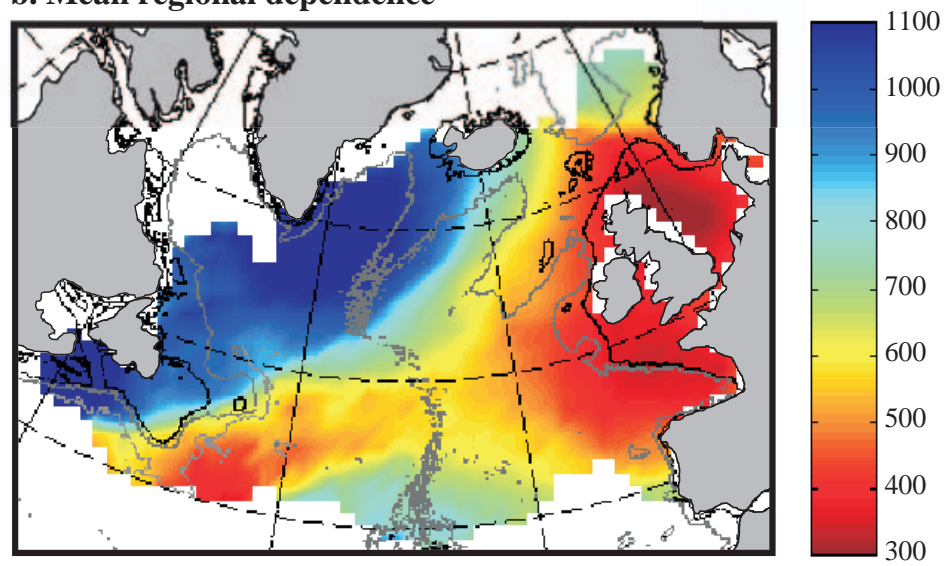

c. Correlations
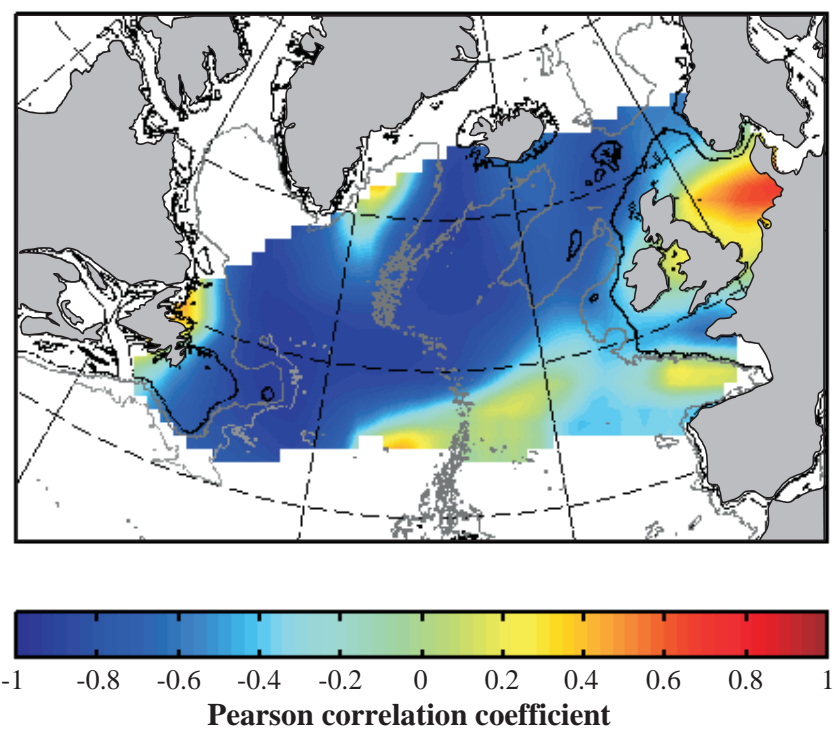

Fig. 4. Mean maps of the diversity of calanoid copepods (a) and its regional dependence (b) in the North Atlantic Ocean and adjacent seas. These maps represent the mean of 8 maps of the regional dependence of diversity produced for each season for daylight and dark periods at a PCSV level of 100. Similarly to Fig. 3, several PCSV levels were tried and gave similar conclusion. c represents the sliding 2-dimensionnal Pearson correlation between a and $\mathrm{b}$ 

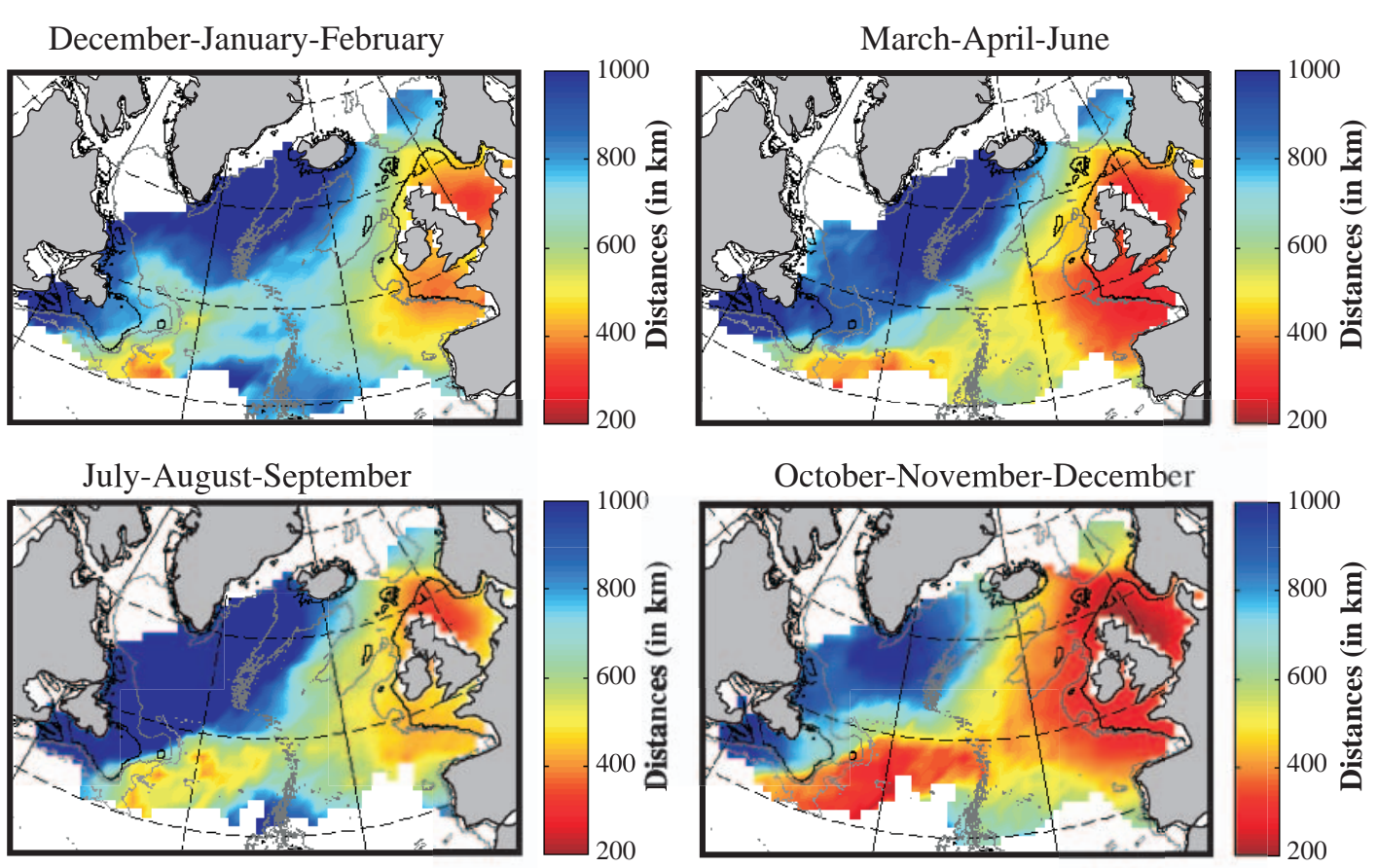

Fig. 5. Seasonal changes in the regional dependence of the diversity of calanoids. Dark periods were only used according to the same procedure utilised by Beaugrand et al. (2001, their Fig. 1)

occurred during the second period in the NE North Sea. Diversity is still high over the southern part of the European shelf edge. A Kruskal-Wallis test performed for each pixel clearly demonstrates that these changes are significant with the exception of coastal areas and the southern North Sea. The spatial dependence of calanoid diversity has significantly increased west of British Isles and decreased over the European shelf and the west European basin (Fig. 7b). Sliding 2-dimensional correlations between diversity and its spatial dependence calculated for both periods (not shown) indicate that the positive relationship in the North Sea has moved northwards sicnce 1987 . The positive relationships seen in the southern part of the Bay of Biscay became negative for the period 1988 to 1999.

\section{DISCUSSION}

\section{Sen's point cumulative semi-variogram}

Sen's point cumulative semi-variogram allowed local behaviour of the regional variable to be examined and its spatial heterogeneity to be assessed (Sen 1989). This represents a great advantage in comparison with the classical semi-variogram, which only examines the regional variable globally. Local semi-variograms, greatly variable, are clearly not adapted for this purpose and Fig. 2 showed that in most cases, they were not interpretable.
The mapping of distances for a fixed PCSV value is of great interest. Local variability and anisotropic behaviour of the regional variable can be visualised and quantified. The selection of the PCSV value is important and results may slightly vary from one threshold to another (Fig. 3). It is highly recommended to use several thresholds. Sen $(1989,1998)$ discussed other technical advantages of this method.

\section{Diversity and spatial dependence of calanoids at diel and seasonal scale}

Mapping of the spatial dependence of the calanoid diversity showed that diversity varies at a smaller spatial scale in neritic than in oceanic regions. At a PCSV fixed to 100, European shelf sea diversity changes during dark periods for distances ranging from 300 to $450 \mathrm{~km}$ (Fig. 4b). Canadian continental shelf sea diversity varies at a greater scale, more than twice the rate in European seas. In oceanic regions, diversity is spatially stable in the Atlantic Arctic province (Longhurst 1998), about 1000 $\mathrm{km}$ at a PCSV $=100$ and in the northern boundary of the subtropical gyre (on average about $800 \mathrm{~km}$ at a PCSV = 100). Lower-scale spatial patterns in calanoid diversity are observed in the Gulf Stream extension (as defined by Beaugrand et al. 2001), in the path of the North Atlantic Current west of the mid-Atlantic ridge and west of Europe. 
a. Diversity of calanoids and NAO
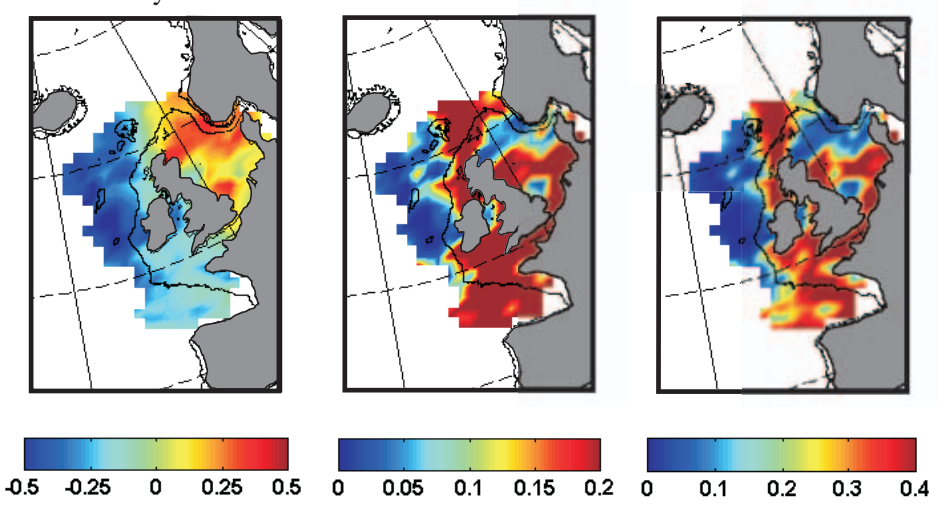

b. Diversity of calanoids and Northern Hemisphere temperature
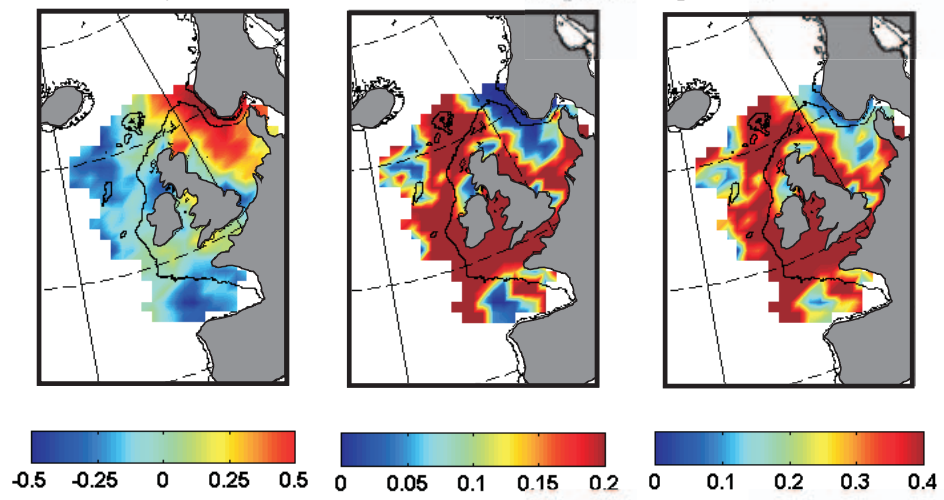

c. Spatial dependence and NAO
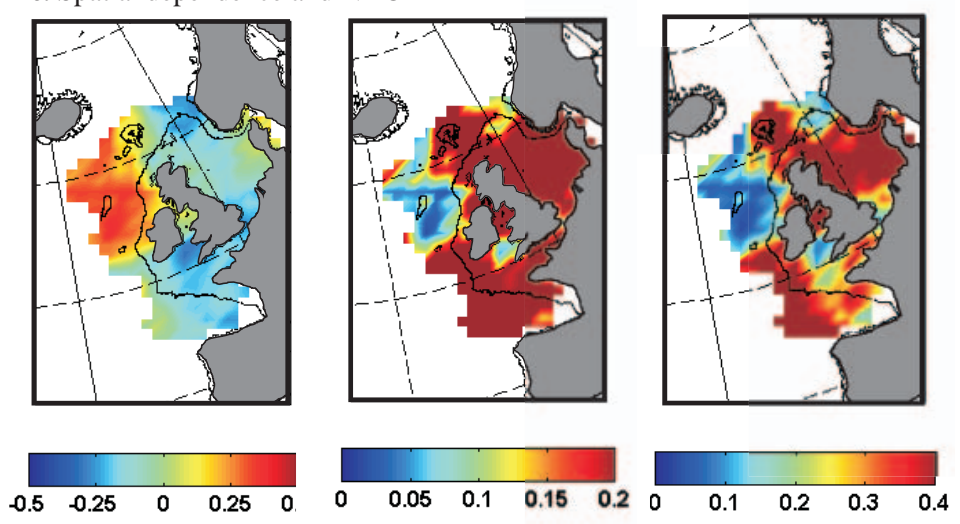

d. Spatial dependence and Northern Hemisphere temperature
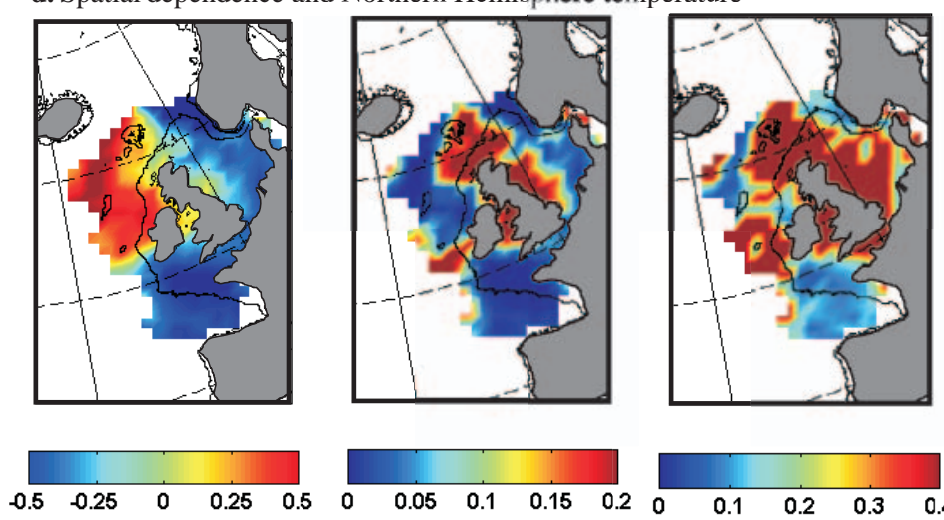

Pearson correlation coefficient

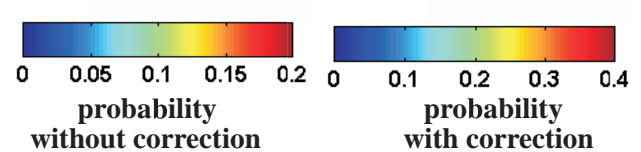

Spatial distribution of eddy kinetic energy and occurrence is strongly heterogeneous in the ocean (Stammer \& Böning 1996, see Fig. 16 in Pingree et al. 1999). Maximum variability is often found in the path of major oceanic surface currents such as the Gulf Stream (Stammer \& Wunsch 1999). Close correspondence exists between the lower-scale spatial variability observed in the Gulf Stream extension and in the path of the North Atlantic Current west of the mid-Atlantic ridge (Fig. 3) and maps of eddy kinetic energy produced by Wunsch \& Stammer (1995), Stammer \& Böning (1996), and Ducet et al. (2000). Eddy activity related to the path of the North Atlantic Current and the Oceanic Polar Front is likely to explain the low scale of spatial variability observed between the subarctic and the northern boundary of the subtropical gyre.

In oceanic areas west of European seas and east of about the mid-Atlantic ridge, diversity also changes at a low spatial scale (Figs. 3 \& 4). Even though eddy energy is weaker in oceanic regions west of Europe, mesoscale eddy activity has been reported in this area (Stammer \& Böning 1996, Read \& Pollard 2001). During the North Atlantic Bloom Experiment (Ducklow \& Harris 1993), spatial changes in chl a and temperature were investigated in regions along the $20^{\circ} \mathrm{W}$ meridian near 48 and $60^{\circ} \mathrm{N}$ between 26 April and 3 June 1989 (e.g. Watson et al. 1991, Robinson et al. 1993, Yoder et al. 1993). Temperature and chl a concentrations were found to be significantly positively correlated providing evidence that physical processes, attributed by the authors to upwelling and mixing, affect the spatial distribution of phytoplankton biomasses.

Two main processes are seen to be important in the generation, energy, frequency and longevity of eddies. First, the presence of eddies west of the British Isles has been ascribed to the path of the North Atlantic Current (White \& Heywood 1995, Bersch et al. 1999, Read \& Pollard 2001). Secondly, it has also been demonstrated that winds are involved in the generation of the mesoscale eddy field (Stammer \& Böning 1996, Stammer \&

Fig. 6. Pearson correlation between the mean annual calanoid diversity and (a) winter NAO index and (b) northern hemisphere temperature. Pearson correlation between the mean annual spatial dependence of calanoid diversity and (c) winter NAO index and (d) northern hemisphere temperatures. In each case, the corrected and not corrected probability for temporal autocorrelation is indicated (see 'Materials and methods') 
a. Mean diversity of calanoid copepods (night observations)
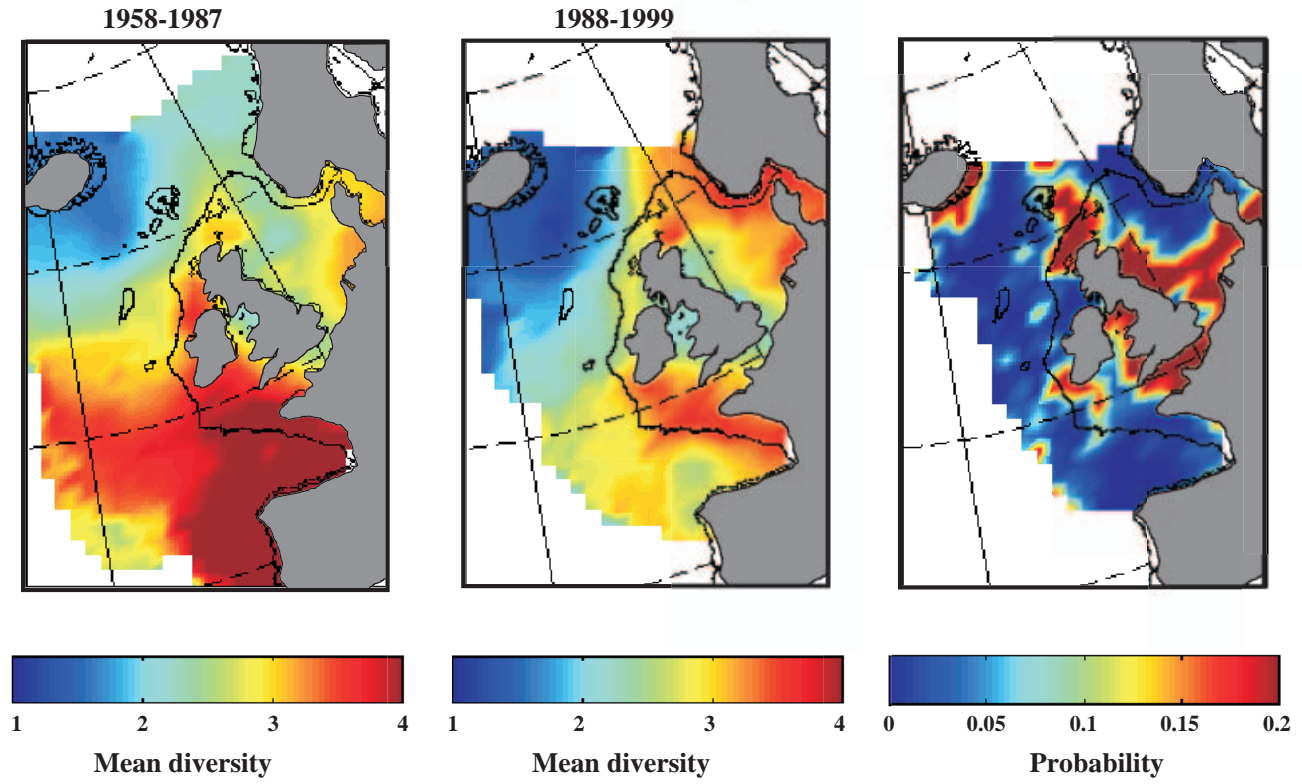

b. Mean regional dependence of calanoid diversity in November-December (night observations)

1958-1987
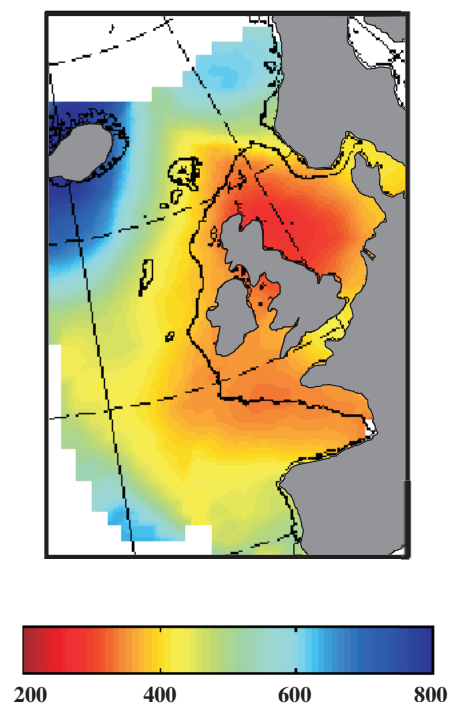

Mean distance (in km)
1988-1999
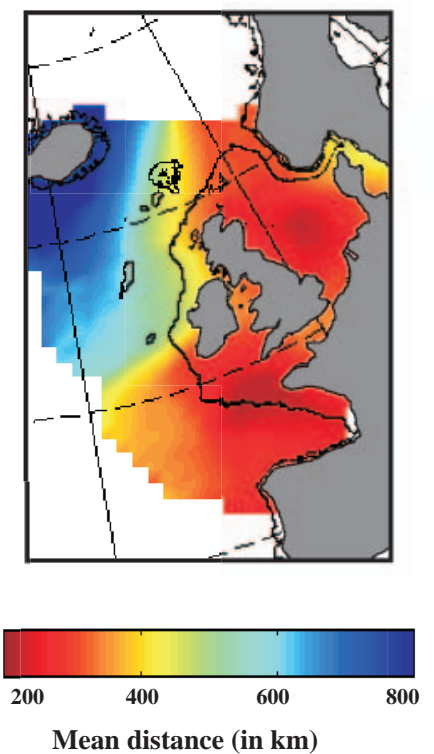
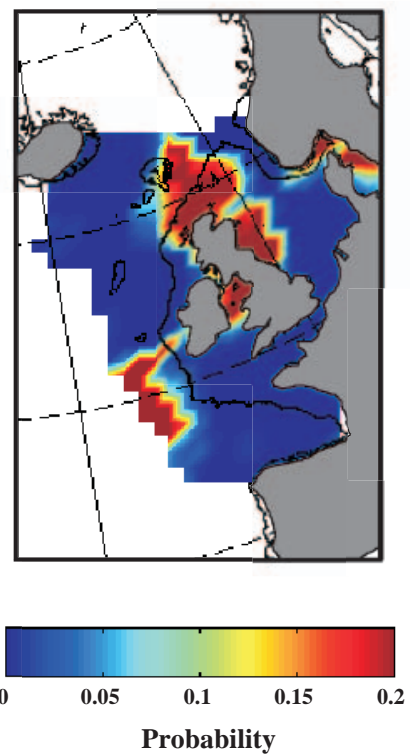

Fig. 7. Mapping of (a) diversity of calanoids and (b) its regional dependence for the periods 1958 to 1987 and 1988 to 1999 . A Kruskal-Wallis test was performed in each pixel to examine where the differences between the 2 periods were significant. The resulting probabilities are also plotted

Wunsch 1999). Seasonal charts of eddy variability produced by Stammer \& Wunsch (1999) show that the strongest production of eddies occurs during autumn. This corresponded with seasonal changes in wind forcing west of the European continental shelf, which also coincides with the maximum low-scale variability in calanoid diversity found in this study (Fig. 5). However, eddy kinetic energy is still elevated in winter in their charts while spatial variability in diversity is at its highest annual level. This result may be explained by the low diversity during this period. Other factors such as the topography (Martin et al. 1998) and the seasonal development of the pycnocline (maximum influence in late summer, Strass et al. 1992) are suspected to also influence the production of eddies, particularly west of the British Isles. 


\section{Relationships between diversity and spatial dependence}

A negative relationship was found between diversity and its spatial dependence in almost all areas. The robustness of this relationship is difficult to assess in the present study as data are spatially autocorrelated because of the use of spatial interpolations. However, the same relationships between diversity and its spatial dependence were detected for each season, at the scale of the North Atlantic Ocean and European seas, which is a good indication of its validity. This indicates that the more local the spatial changes in diversity are, the higher the diversity is. However, this result should not be extrapolated to the whole ocean or considered as a primary factor that explains regional differences in diversity. Examination of a global scale map of planktonic foraminera diversity (Rutherford et al. 1999) and maps of eddy kinetic energy (Stammer \& Wunsch 1999, Ducet et al. 2000) does not visually show a strong link in subtropical and equatorial areas. The central gyre of the North Pacific, which is characterised by high diversity (McGowan \& Walker 1985, McGowan 1990), has a low average eddy kinetic energy (Ducet et al. 2000). Thus, the link between diversity and eddy kinetic energy is not likely to be true at a global scale but may be a characteristic of the northern North Atlantic Ocean pelagic ecosystems. Furthermore, the negative relationship between diversity and spatial dependence seems to become positive in the northern boundary of the subtropical gyre (Fig. 4c). A large area in the North Sea also exhibits a positive link between diversity and its spatial dependence.

Beaugrand et al. (2001) have emphasised the importance of local physical processes in the regulation of spatial distributions of pelagic diversity in the northern North Atlantic. Beaugrand et al. (2000) demonstrated a pronounced local as well as an east-west asymmetry in the diversity of calanoids in the same area. The warm North Atlantic and European shelf edge currents were seen to be strongly involved in this spatial pattern (Beaugrand et al. 2001, 2002). This study strengthens this hypothesis and introduces more elements which improve interpretation of spatial changes in the pelagic diversity in this area. Factors implied in the spatial regulation of the diversity are primarily physical in the region of interest. Biological factors such as competition (Pianka 1966) and predation (Paine 1966) do not seem to play an important role. Rohde (1992) reviewed major hypotheses to explain changes in diversity from the poles to the tropics. He concluded in his review and other subsequent papers (e.g. Rohde et al. 1993, Rohde 1997) that energy was the main factor responsible for this difference, although other authors argued that this pattern could be explained by the area
(Rosenzweig 1995, Rosenzweig \& Sandlin 1997), the history (Crame \& Clarke 1998) or a mid-domain effect (Colwell \& Lees 2000). Transposing Rohde's (1992) view to the regulation of diversity at the scale of our spatial area, in agreement with Beaugrand et al. (2001, 2002), we think that energy, its intensity (temperature or hydrodynamics) and frequency (seasonal and annual fluctuations in temperature and/or hydrodynamics) is strongly involved in the spatial control of diversity in the North Atlantic Ocean.

\section{Annual and long-term changes in diversity, spatial variability and climatic indices}

Diversity was found to be positively correlated with the winter NAO index in the northern North Sea and negatively correlated in oceanic regions west of the British Isles. Positive correlations were also found between northern hemisphere temperatures and diversity in the northern part of the North Sea while negative correlations were detected in some oceanic regions such as the Bay of Biscay. The significant change in probability, when the correction to account for the autocorrelation is applied, indicates that northern hemisphere temperature signals and/or spatial dependence time series are serially correlated.

Beaugrand et al. (unpubl.) have recently shown that a significant biogeographical shift in the whole community of calanoid copepods has been occurring at the scale of the North Atlantic Ocean. In Europe, the mean number of warm-water pseudo-oceanic, oceanic and neritic species moved northwards, while the mean diversity of colder-water species has significantly decreased in their southern range of spatial distribution. Significant correlations were found between these biogeographical changes, the NAO and northern hemisphere temperatures. The consistency of these results provides evidence that the low-frequency plankton variability in this region may have been governed by climatic warming (Intergovernmental Panel on Climate Change 2001) since at least the end of the 1970s. This was particularly strong in the northern part of the European shelf edge and in the North Sea. However, the global increase in temperature may not only act directly on plankton physiology or phenology, but may also manifest itself through existing hydroclimatic channels such as the NAO, which in turn influences the spatial distribution of plankton. Our results are in agreement with these findings for the northern part of the North Sea, but the use of the diversity index failed to detect these changes throughout the European shelf edge.

The relationship between spatial dependence in calanoid diversity and both climatic indices is positive 
in oceanic areas west of the British Isles. This means that during a high NAO, the spatial variability in diversity changes at a higher scale in the ocean. This is slightly negatively correlated elsewhere with the NAO index, although this is not statistically significant. A greater negative correlation is observed for northern hemisphere temperatures, although also not statistically correlated when the correction to account for autocorrelation is applied. At this stage, it is difficult to propose a reasonable mechanistic explanation which may link spatial dependence to temperatures and the NAO. The positive phase of the NAO, possibly influenced by the global increase in temperatures (Hurrell et al. 2001), has emphasised the contrast between oceanic and neritic regions with the notable exception of the Bay of Biscay. This has increased the spatial scale of variability over the ocean and has decreased it over shallow regions and in the Bay of Biscay. Processes such as the path of currents, wind direction and intensity and change in pycnocline depth may also play a role, but the sequence seems to differ from that involved at a seasonal scale.

Many changes in the biological composition of the North Sea marine ecosystems were detected at the end of the 1980s (e.g. Lindley et al. 1990, 1993, Greve 1994, Reid et al. 1998). For example, the doliolid Doliolum nationalis, the dinoflagellate Ceratium extensum and the siphonophore Muggiaea atlantica, usually found in oceanic water, were detected in the central North Sea in 1987 (Lindley et al. 1990, Greve 1994). Reid et al. (1998) also reported a sharp change in an indicator of phytoplanktonic biomass in the North Sea after 1987. This cascade of biological events has been named a 'regime shift' by Reid et al. (2001a). This has been attributed to an exceptional inflow of oceanic water due to an increase in the shelf edge current, possibly mediated by the recent persistent positive phase in the North Atlantic Oscillation (Reid et al. 2001b, Reid \& Beaugrand in press). Our results clearly show the consequence of this regime shift on calanoid diversity with a significant increase in diversity that occurred in the northern and central North Sea. In contrast, a clear decrease is detected in the oceanic areas while the diversity is still high over the European shelf edge. A significant change in the scale of spatial variability has occurred since 1987 (Fig. 8).

\footnotetext{
Acknowledgements. The authors are grateful to all past and present members and supporters of the Sir Alister Hardy Foundation for Ocean Science whose continuous efforts have allowed the long-term establishment and maintenance of the CPR data-set. We are particularly grateful to Robin D. Pingree, P. Christopher Reid, J. Alistair Lindley and the 3 anonymous referees for advice and comments on the manuscript. The survey depends on the owners, masters and crews of the ships that tow the CPRs. This research was supported by the
}

European Community Research Project No. MAS3-CT985058, The Netherlands (contract RKZ595) and the 'Programme National en environnement côtier, thème: influence des facteurs hydroclimatiques ou anthropiques sur la variabilité spatio-temporelle des populations et écosystèmes marins' (PNEC art 4).

\section{LITERATURE CITED}

Beaugrand G, Edwards M (2001) Comparison in performance among four indices used to evaluate diversity in pelagic ecosystems. Oceanol Acta 24:467-477

Beaugrand G, Reid PC, Ibañez F, Planque P (2000) Biodiversity of North Atlantic and North Sea calanoid copepods. Mar Ecol Prog Ser 204:299-303

Beaugrand G, Ibañez F, Lindley JA (2001) Geographical distribution and seasonal and diel changes of the diversity of calanoid copepods in the North Atlantic and North Sea. Mar Ecol Prog Ser 219:189-203

Beaugrand G, Ibañez F, Lindley JA, Reid PC (2002) Diversity of calanoid copepods in the North Atlantic and adjacent seas: species associations and biogeography. Mar Ecol Prog Ser 232:179-195

Bersch M, Meincke J, Sy A (1999) Interannual thermohaline changes in the northern North Atlantic 1991-1996. DeepSea Res Part II 46:55-75

Box GEP, Jenkins GW (1976) Time series analysis: forecasting and control. Holden-Day, San Francisco

Chatfield C (1989) The analysis of time series: an introduction, 4th edn. Chapman \& Hall, London

Chelton DB (1984) Commentary: short-term climatic variability in the northeast Pacific Ocean. In: Pearcy W (ed) The influence of ocean conditions on the production of salmonids in the North Pacific. Oregon State University Press, Corvallis, p 87-99

Colebrook JM (1960) Continuous Plankton Records: methods of analysis, 1950-59. Bull Mar Ecol 41:51-54

Colebrook JM (1975) The Continuous Plankton Recorder survey: automatic data processing methods. Bull Mar Ecol 8: 123-142

Colebrook JM (1981) Continuous Plankton Records: persistence in time-series of annual means of abundance of zooplankton. Mar Biol 61:143-149

Colebrook JM (1982) Continuous Plankton Records: persistence in time-series and the population dynamics of Pseudocalanus elongatus and Acartia clausi. Mar Biol 66: 289-294

Colebrook JM (1984) Continuous Plankton Records: relationships between species of phytoplankton and zooplankton in the seasonal cycle. Mar Biol 83:313-323

Colebrook JM (1985) Sea surface temperature and zooplankton, North Sea, 1948 to 1983. J Cons 42:179-185

Colebrook JM (1991) Continuous Plankton Records: from seasons to decades in the plankton of the North-East Atlantic. In: Kawasaki T, Tanaka S, Toba Y, Taniguchi A (eds) Long-term variability of pelagic fish population and their environments. Pergamon Press, Oxford, p 29-45

Colwell RK, Lees DC (2000) The mid-domain effect: geometric constraints on the geography of species richness. Trends Ecol Evol 15:70-76

Crame JA, Clarke A (1998) The historical component of marine taxonomic diversity gradients. In: Ormond RFG, Gage JD, Angel MV (eds) Marine biodiversity: patterns and processes. Cambridge University Press, Cambridge, p 258-273 
Dickson RR, Turrell WR (2000) The NAO: the dominant atmospheric process affecting oceanic variability in home, middle and distant waters of European Atlantic salmon. In: Mills D (ed) The ocean life of Atlantic salmon: environmental and biological factors influencing survival. Fishing News Books, Bodmin, p 92-115

Diggle PJ (1990) Time series: a biostatistical introduction. Clarendon Press, Oxford

Ducet N, Le Traon PY, Reverdin G (2000) Global high-resolution mapping of ocean circulation from TOPEX/Poseidon and ERS-1 and -2. J Geophys Res 105:19477-19498

Ducklow HW, Harris RP (1993) Introduction to the JGOFS North Atlantic Bloom Experiment. Deep-Sea Res Part II 40:1-8

Frontier S, Pichot-Viale D (1993) Ecosystèmes: structure, fonctionnement, évolution. Masson, Paris (in French)

Garret C, Petrie B (1981) Dynamical aspects of the flow through the strait of Belle Isle. J Phys Oceanogr 11:376-393

Geary RC (1954) The contiguity ratio and statistical mapping. Incorp Statist 5:115-145

Greve W (1994) The 1989 German Bight invasion of Muggiaea atlantica. ICES J Mar Sci 51:355-358

Grioche A, Koubbi P, Sautour B (1997) Ontogenic migration of Pleuronectes fletus larvae in the eastern English Channel. J Fish Biol 51(Suppl):385-396

Haury LR, McGowan JA (1998) Time-space scales in marine biogeography. Intergov Oceanogr Com Workshop Rep 142:163-170

Haury LR, McGowan JA, Wiebe PH (1978) Patterns and processes in the time-space scales of plankton distributions. In: Steele JH (ed) Spatial pattern in plankton communities. Plenum Press, New York, p 277-327

Hays GC (1994) Mesh selection and filtration efficiency of the Continuous Plankton Recorder. J Plankton Res 16:403-412

Hurrell JW (1995) Decadal trends in the North Atlantic Oscillation: regional temperatures and precipitations. Science 269:676-679

Hurrell JW, Yochanan K, Visbeck M (2001) The North Atlantic Oscillation. Science 291:603-605

Ibañez F, Etienne M (1991) Le filtrage des séries chronologiques par l'analyse en composantes principales de processus (ACPP). J Res Océanogr 16:27-33

Intergovernmental Panel on Climate Change (2001) Climate change 2001: the scientific basis. Cambridge University Press, Cambridge

Journel AJ, Huijbregts CJ (1978) Mining geostatistics. Academic Press, New York

Kope RG, Botsford LW (1990) Determination of factors affecting recruitment of chinook salmon, Oncorhynchus tshawytscha, in central California. Fish Bull 88:257-269.

Lam NSN (1983) Spatial interpolation methods: a review. Am Cartogr 10:129-149

Legendre P, Legendre L (1998) Numerical ecology, 2nd edn. Elsevier Science, Amsterdam

Levin SA (1992) The problem of pattern and scale in ecology. Ecology 73:1943-1967

Lindley JA, Roskell J, Warmer AJ, Halliday NC, Hunt HG, John AWG, Jonas TD (1990) Doliolids in the German Bight in 1989: evidence for exceptional inflow into the North Sea. J Mar Biol Assoc UK 70:679-682

Lindley JA, Williams R, Hunt HG (1993) Anomalous seasonal cycles of decapod crustacean larvae in the North Sea plankton in an abnormally warm year. J Exp Mar Biol Ecol 173:47-65

Longhurst A (1998) Ecological geography of the sea. Academic Press, London

Lundberg P, Ranta E, Ripa J, Kaitala V (2000) Population variability in space and time. Trends Ecol Evol 15:460-464
Mann KH, Lazier JRN (1996) Dynamics of marine ecosystems: biological-physical interactions in the oceans, 2nd edn. Blackwell Science, Oxford

Margalef R (1979) The organisation of space. Oikos 33: 152-159

Martin AP, Wade IP, Richards KJ, Heywood KJ (1998) The PRIME eddy. J Mar Res 56:439-462

Matheron G (1962) Traité de géostatistique appliquée. EBDRGE minières, Paris

McGowan JA (1990) Species dominance-diversity patterns in oceanic communities. In: Woodwell GM (ed) The Earth in transition. Cambridge University Press, Cambridge, New York, p 395-421

McGowan JA, Walker PW (1985) Dominance and diversity maintenance in an oceanic ecosystem. Ecol Monogr 55:103-108

Merriam DF, Sondergard MA (1988) A reliability index for pairwise comparison of thematic maps. Geologisches Jahrbuch A104:433-446

Moran PAP (1950) Notes on continuous stochastic phenomena. Biometrika 37:17-23

Paine RT (1966) Food web complexity and species diversity. Am Nat 100:65-74

Pianka ER (1966) Latitudinal gradients in species diversity: a review of concepts. Am Nat 100:33-46

Pingree RD, Garcia-Soto C, Sinha B (1999) Position and structure of the Subtropical/Azores front region from combined Lagrangian and remote sensing (IR/altimeter/SeaWiFS) measurements. J Mar Biol Assoc UK 79:769-792

Planque B (1996) Spatial and temporal fluctuations in Calanus populations sampled by the Continuous Plankton Recorder. PhD thesis, Université Pierre et Marie Curie, Paris

Planque B, Fromentin JM (1996) Calanus and environment in the eastern North Atlantic. I. Spatial and temporal patterns of C. finmarchicus and C. helgolandicus. Mar Ecol Prog Ser 134:101-109

Planque B, Hays GC, Ibañez F, Gamble JC (1997) Large scale spatial variations in the seasonal abundance of Calanus finmarchicus. Deep-Sea Res Part I 44:315-326

Platt T, Sathyendranath S (1994) Scale, pattern, and process in marine ecosystems. In: Giller PS, Hildrew AG, Raffaelli DG (ed) Aquatic ecology. Scale, pattern and process. Blackwell Scientific Publications, Cambridge, p 593-599

Pyper BJ, Peterman RM (1998) Comparison of methods to account for autocorrelation analyses of fish data. Can J Fish Aquat Sci 55:2127-2140

Read JF, Pollard RT (2001) A long-lived eddy in the Iceland basin 1998. J Geophys Res C106:11411-11421

Reid PG, Beaugrand G (in press) Interregional biological responses in the North Atlantic to hydrometeorological forcing. In: Sherman K, Skjoldal H-R (ed) Changing states of the Large Marine Ecosystems of the North Atlantic. Elsevier Science, Amsterdam

Reid PC, Edwards M, Hunt HG, Warner AJ (1998) Phytoplankton change in the North Atlantic. Nature 391:546

Reid PC, Borges M, Svenden E (2001a) A regime shift in the North Sea circa 1988 linked to changes in the North Sea horse makerel fishery. Fish Res 50:163-171

Reid PC, Holliday NP, Smyth TJ (2001b) Pulses in eastern margin current with higher temperatures and North Sea ecosystem changes. Mar Ecol Prog Ser 215:283-287

Robinson AR, McGillicuddy DJ, Calman J, Ducklow HW and 8 others (1993) Mesoscale and upper ocean variabilities during the 1989 JGOFS bloom study. Deep-Sea Res Part II 40:9-35

Rohde K (1992) Latitudinal gradients in species diversity: the search for the primary cause. Oikos 65:514-527 
Rohde K (1997) The larger area of the tropics does not explain latitudinal gradients in species diversity. Oikos 79:169-172

Rohde K, Heap M, Heap D (1993) Rapoport's rule does not apply to marine teleosts and cannot explain latitudinal gradients in species richness. Am Nat 142:1-16

Rosenzweig ML (1995) Species diversity in space and time. Cambridge University Press, Cambridge

Rosenzweig ML, Sandlin EA (1997) Species diversity and latitudes: listening to area's signal. Oikos 80:172-176

Rutherford S, D'Hondt S, Prell W (1999) Environmental controls on the geographic distribution of zooplankton diversity. Nature 400:749-753

Sen Z (1989) Cumulative semi-variogram models of regionalized variables. Math Geol 21:891-903

Sen Z (1998) Regional seismicity at Turquey. Math Geol 30:767-787

Stammer D, Böning CW (1996) Generation and distribution of mesoscale eddies in the North Atlantic Ocean. In: Krauss K (ed) The warmwatersphere of the North Atlantic Ocean. Gebrüder Bontraeger, Berlin, p 159-193

Stammer D, Wunsch C (1999) Temporal changes in eddy energy of the oceans. Deep-Sea Res Part II 46:77-108

Stommel H (1963) Varieties of oceanographic experience. Science 139:572-576

Strass V, Leach H, Woods JD (1992) On the seasonal devel-

Editorial responsibility: Otto Kinne (Editor),

Oldendorf/Luhe, Germany opment of mesoscale variability: the influence of the seasonal pycnocline formation. Deep-Sea Res 39: 1627-1639

Tsuda A, Sugisaki H, Ishimaru T, Saino T, Sato T (1993) White-noise-like distribution of the oceanic copepod Neocalanus cristatus in the subarctic North Pacific. Mar Ecol Prog Ser 97:39-46

Wackernagel H (1995) Multivariate geostatistics: an introduction with applications. Springer-Verlag, Berlin

Warner AJ, Hays GC (1994) Sampling by the Continuous Plankton Recorder survey. Prog Oceanogr 34:237-256

Watson AJ, Robinson C, Roberson JE, Williams PJIB, Fasham MJR (1991) Spatial variability in the sink for atmospheric carbon dioxide in the North Atlantic. Nature 350:50-53

White MA, Heywood KJ (1995) Seasonal and interannual changes in the North Atlantic subpolar gyre from Geosat and TOPEX/POSEIDON altimetry. J Geophys Res C 100: 24931-24941

Wunsch C, Stammer D (1995) The global frequency-wavenumber spectrum of oceanic variability estimated from TOPEX/POSEIDON altimetric measurements. J Geophys Res C 100:24895-24910

Yoder JA, Aiken J, Swift RN, Hoge FE, Stegmann PM (1993) Spatial variability in near-surface chlorophyll a fluorescence measured by Airborne Oceanographic Lidar (AOL). Deep-Sea Res Part II 40:37-53

Submitted: October 16, 2001; Accepted: January 31, 2002 Proofs received from author(s): April 24, 2002 